\title{
Analysis of Risk Assessment for Financing Small- Medium Enterprises' Project and the Impact of Lending Decision Making
}

\author{
Ziyodilloev Khushnud* \\ School of Economics \\ Beijing Technology and Business \\ University \\ Beijing, China \\ xushnud.ziyodilloyev@mail.ru
}

\author{
Qingjie Zhou \\ School of Economics \\ Beijing Technology and Business \\ University \\ Beijing, China \\ zhouqj@btbu.edu.cn
}

\author{
Yan Li \\ International Business School \\ Yunnan University of Finance and \\ Economics \\ Kunming, China \\ culiyan2002@163.com
}

\begin{abstract}
This research paper is an attempt to analyze risk assessment of financing Small-Medium Enterprises' (SMEs') projects and to investigate on the roles of lending managers and their decision making, also to demonstrate that it has a huge impact on project success, influence to implement bank financing projects. Therefore, the paper focused on identifying strong risk assessment for the SMEs and in general aims to identify various risks that Aloqabank managers are facing currently to finance SMEs' project. Despite the fact that the research paper tried to find out various tools and techniques dealt within bank financing projects. Furthermore, case study approached to identify different risks and to analyze risk assessment of SMEs' projects. According to questionnaires' results and case study analysis, the evidence that the key indicator signals to decision making and to give loan for the projects are past performance of SMEs, financial standing, ordering collateral and business project competence, all affected the likelihood of a lending manager supporting SMEs and credit request.
\end{abstract}

Keywords: risk assessment, Small-medium enterprises (SMEs), financing SMEs' project, lending managers, Aloqabank

\section{INTRODUCTION}

Small-Medium Enterprises (SMEs) play to create jobs opportunities and generating profit for low income nation, it is a major role of them, enterprises support social stability and effect to the development of a private sector dynamically. So, need to mention that access to financial source is main task in the economy for developing SMEs sector. In economy of Uzbekistan, development of SMEs' areas are becoming a significant increasing and have effect factor in economic growth and employment, also to stimulate domestic demand and industry sector. In the past decade, the banks have played a significant role in supporting and helping small - medium enterprises around the world, gain great access to financing projects. Therefore, banks work to grow up access of SMEs to financial resources in developing countries by provide loan for their projects. Small-medium enterprises (SMEs) are always a significant part of any economy during development. Most times small enterprises are the supply chain for the bigger corporates and hence adequate resource of SMEs in the country is main key impact on the GDP growth. The main obstacle to the development of SMEs' sector is the lack of financing support by banks. As we know that bank has dominated characteristic in most of countries economy, they are the key resources of financing for SMEs' project.-leveled equations, graphics, and tables are not prescribed, although the various table text styles are provided. The formatter will need to create these components, incorporating the applicable criteria that follow.

\subsection{Research Rationale}

SMEs are given loan decisions access traditionally lead to skilled managers and specific expertise during holding project. Mainly, for this approach designed using qualitative data as well as SME's financial report and audit analysis help to lending officers who enough skilled. Also this can take more times look to project concern, we can say like site learning, ask questions, conducting questionnaires and interviews, also is prepared reports with the project managers. Therefore, SMEs' credit, which amounted to 46.9 percent of total banks loan for SMEs sector of Uzbekistan, in 2018. Therefore, new history that leading to them being perceived as high risks by lending managers for financing projects. Aloqabank is one of jointstock commercial bank, supporting SMEs' project in large scale have they have challenges to combine various factors during credit assessment for SMEs.

Mainly, the loan process to SMEs represents a critical thinking for the credit manager, one of task. It helped to ensure what loan consider in all aspect of the SMEs, managers be sure they are capable for loan and can repay credit, also its fee for using in time period, managers refused giving loan to those who are not capable. So, many researches result show that managers need to create and develop specific method which help them to reduce the risks and also uncertainly in managing and controlling loans for SMEs. In Aloqabank, many banks' lending managers are facing the huge problems within their project for establishing a strong risk assessment framework for financing project of SMEs in order to maximize their main goal what to get profit, repay loan and to gain competitive advantage over their partners. Also, investigate on which factors are vital significant for SMEs. 
Relationship between banks and SMEs segment are particularly complicated, also need to mention give the lack of diversified financial segment, undefined methods and procedures, badly small enterprises' insufficient experience. Nowadays, however, more attention is given to SMEs by lending managers, as is evidenced by the fact what many banks created separate departments specializing in SMEs. This research paper focuses on examine Aloqabank risk assessment of financing SMEs project, banking managing risks procedures, the importance of knowledgeable lending decision makers, strategy and their impact on promote bank project succeed.

\section{THEORETICAL BACKGROUND}

\section{A. Lending decision making for financing SMEs' project}

Many researchers' paper approached to examine the relationship between banks financing and SMEs' project. Therefore, reviewed papers placed significant focus on identify and discuss variety types risks in SMEs, because the point that risk identification is always an important prerequisite for the later risk assessment and analyze risk assessment practice for bank financing SMEs' project. It should be noted that this paper contributes to the national lending managers of banks and focus on main problems of Aloqabank. Till now, papers have published in Uzbekistan related to banking sphere but existing papers do not analyzed deeply risk assessment and focused on decision making. (Fletcher, 2008), suggested for the lending manager that a strong financial standing is compensate for the risk tolerance. Managers focus on ordering collateral, because SMEs with solid collateral likelihood loan is granted significantly during taking loan as a low. Importantly, Thun T., (2016), study analyzed 68 German SMEs' activities and research found that supply chain risks in SMEs' project. Thun suggests that SMEs need to offer an increasingly range of products to meet needs by customers. (Gilmore et al, 2004), he focused on management and employees risks for the SMEs' project in his research. The point that 40 British project managers interviewed by Gilmore and he suggested that every business sector is exposed to avoid or loss knowledge, with skilled and experienced employees in valuable and reliable information. Mainly, knowledge management may constitute problems for the SMEs.

Moreover (Wilson, 2013) research study which did with 16 qualitative interviews and quantitative survey of 124 SMEs in the UK, found e-business and technological risks for the SMEs' project, during research he identified that online safety is more dangerous risk if SMEs' project deal with e-business. Wilson indicated that currently SMEs are exposed to various online threats which credit card fraud, cyber-attacks during holding project, also e-mail abuse identifying theft and others. According to Marcelinp (May, 2014), SMEs growth is accomplished in every project of the SMEs, on the other hand, all these pose significant risks due to SEMs do not approach or use techniques and know-how required which enable to run project growth efficiently and effectively. And (Priem, 2009) suggested that risk assessment is specific approaches and process which bank approach comprehensive and methodical, investigate on risks identify and analyze during project events and process of the activities to achieve strategic goals, sustain profit within all activity and across financial operations.

Many papers showed that banks' lending managers are facing more challenges and difficulties due to a small decline financing in loan quality. According to (Kim at al., 2001) the root of bad debts or poor loan quality deal with managers' skills and the mechanism of data processing when decide loan for the existing SMEs. Also, (Kim, 2006), stated that the main problems start from beginning which the stage application for loan and expand issues at every stages, during loan approval, monitoring, identify risks, control project when for the lending managers does not have existence of guidelines in risk assessment strategy. During assessing risks lending officers regarding credit processing, bank policies or procedures, maybe the guidelines are incomplete or very weak Baas, T. and Schrooten, M. (2011) think that risk assessment of the SMEs emphasize on the capabilities of the business project to anticipate different changes, he stated that not only avoid project's risks. We need to say that risk avoidance shows what waiting for the bad things, events to happen then approach it. Indeed, data indicated that most lending managers choose to avoid SMEs' project risks in banks of Uzbekistan. According to Uzbek researcher and economist Abdullaeva Sh. (2002), risk assessment for the bank financing projects enable avoiding loses, profit maximization, help to find ways of restrictions in risks SMEs' project. We can say that risks are averted by ordinary policies and procedures, also show the way to shift risks.

\section{B. Risk assessment of bank financing SMEs' project}

According to findings from literatures is that there are various approaches for assessing risks of the SMEs by lending manager deal with choose processes for the risk assessment and investigate on reduce any loses. According to some researches in this field (Taylor, 2006), (K. Tony, 2016), SMEs' project risk management methods changing, mainly moved from quantitative to structured assessing risks process which with view of the understanding and also embedding management across all SMEs during implement project and life cycle of the project. Also, decision makers can influence significantly for SMEs' project view and success. Moreover, (Carey, A., and H. Anderson, 2001), every bank efforts to proper and homogenize loan decision making across credit managers. It is important to mention that loan decision made by lending officers who has vary level of giving loan experiences. According to (Surgue, 2009), banks' lending managers need to have strong incentive to finance bank credit to new start project, especially repaying is in good condition, approach financial sources to the risky events, projects. Lending officers focus on develop specific measures to safeguard against any loses for the bank. According to $\mathrm{S}$. Barton (1989), (Lane, 2011), (Al-Tamimi, 2007), managerial skills and ownership can be influenced by regulatory regimes in the bank; he found that can effect through framework of the banks' moral hazard. Also, his study suggest that lending officers in banks will enable to do efficiently and judging risks with effectively in every level. It is important to mention that bank face and also risks reward trade off.

\section{RESEARCH DATA AND METHODOLOGY}

\section{A. Data collection}

During conducting research, mainly primary data collected from distributing various questionnaires to lending managers who decide loan for SMEs' project in the Aloqabank. Indeed, 
researches conduct qualitative and quantitative, those using primary alternatives to all researchers. All the questionnaires were consisted three key parts which two parts include 33 questions and final part consist of 2 open questions, designed to know more details from credit managers of Aloqabank, across the managers' attitude towards specifically and understanding of risks and implementing risk assessment. Also, questionnaires distributed to the 89 lending managers who decided loan for SME sector, in the end only 80 managers, respondents answered and returned filled questions, need to mention that a response rate of yielding is 86.25 percent. Therefore, questions investigated on risk assessment goals for SMEs, techniques and process emphasize on implementing and understanding risk assessment of financing SMEs' project by Aloqabank lending managers and their approach that the manager take towards risks and risk control of SMEs' project.

\section{B. Research data method}

This paper approached quantitative analyses which investigate on effectiveness assessment of financing SMEs' project, illustrate identifying risks practice and management tools by lending managers. Research paper data collected from two main different sources which these are internal and external to the subject of research. We used to collect information primary and secondary data for conducting this paper it is necessary to say that all secondary sources are gathered figures, statistics and facts collected to get information, such our secondary data gathered from various literature, it may include electronic sites, books, different journal, research paper which done by other people before and other, bank annual reports, SMEs management reports, published internal papers and policies.

\section{Data analysis method}

Data analysis were designed in term of the data accepted, received and also showed the participants' demographic diagrams, figures, tables using to demonstrate bank's risk assessment for bank financing project of SMEs' in Aloqabank. Calculated Cronbach's alpha for every sectors where investigated by using questionnaire and then for the data as a whole. Cronbach's alpha measured the consistency with managers approach questions across their knowledge, experience and specification. It helped us during analysis data the reliability various research variables. During testing the hypotheses, we applied conjoint experiment. It helped us within conducting research, to investigate concurrent reports, which challenges of SMEs' project, difficulty for lending decision to loan. Subject regression analysis conducted on Research objectives. It is a main way of analysis relating variables to each other by regression analysis. The study uses a single case project to analyze properly; also advantage of analysis case project is what researchers focus on one case to provide an in-depth, holistic view on a specific topic.

\section{Research limitations}

The research paper performance statistics are limited. Nevertheless, the research paper can obtain financial reports and related data of the Aloqabank, manager's reports and other significant information. So, it was some limitations during conducting current research, such as to find specific historical information, data, time limitation, some cost issues, the size of subject area, also some data confident.

\section{ECONOMETRIC RESULTS AND DATA ANALYSIS}

\section{A. Cronbach alpha result}

We used Cronbach's alpha to estimate reliability variables. Indeed, $\alpha$ can be indicated correlation of two tests which expect same construct. It is important to mention that Cronbach's alpha shows average covariance items and variance score. This formula is a function testing various items. The formula created by Lee Cronbach first time, in 1951. We addressed to the objectives by this formula and found relationship among them. Cronbach's alpha tests were conducted using SPSS 20.0 program for internal consistency of the scales in use the current study. The test results (see table 1) demonstrate that the measure has a Cronbach's alpha amount exceeds the standard cut-off point 0.700 . Therefore, three scales achieved strong reliability, in fact indicating good internal consistency.

TABLE I. ANALYSING FOUR MAIN QUESTIONS TO FIND OUT RESULT FOR OBJECTIVES AND RELIABILITY STATISTICS

\begin{tabular}{|c|c|c|}
\hline Key questions & \multicolumn{2}{|c|}{ Reliability statistics } \\
\hline \multirow{2}{*}{$\begin{array}{l}\text { Understanding and implementing } \\
\text { risk assessment for the bank } \\
\text { financing SMEs' project to what } \\
\text { extent done by lending managers? }\end{array}$} & $\begin{array}{l}\text { Cronbach's } \\
\text { Alpha }\end{array}$ & $\begin{array}{l}\mathrm{N} \text { of Items } \\
\text { (questions) }\end{array}$ \\
\hline & 0.630 & 5 \\
\hline \multirow{3}{*}{$\begin{array}{l}\text { Which techniques and tools } \\
\text { available in the bank for risks } \\
\text { assessment of the SMEs' project? }\end{array}$} & \multicolumn{2}{|c|}{ Reliability Statistics } \\
\hline & $\begin{array}{l}\text { Cronbach's } \\
\text { Alpha }\end{array}$ & $\begin{array}{l}\text { N of Items } \\
\text { (questions) }\end{array}$ \\
\hline & 0.848 & 7 \\
\hline \multirow{3}{*}{$\begin{array}{l}\text { How the lending manager combine } \\
\text { various factors during credit } \\
\text { assessment and to investigate which } \\
\text { these factors are significant? }\end{array}$} & \multicolumn{2}{|c|}{ Reliability Statistics } \\
\hline & $\begin{array}{l}\text { Cronbach's } \\
\text { Alpha }\end{array}$ & $\begin{array}{l}\mathrm{N} \text { of Items } \\
\text { (questions) }\end{array}$ \\
\hline & 0.656 & 6 \\
\hline \multirow{3}{*}{$\begin{array}{l}\text { How examine that Basel agreement } \\
\text { has assisted or hindered risk } \\
\text { assessment in the bank for financing } \\
\text { SMEs' project? }\end{array}$} & \multicolumn{2}{|c|}{ Reliability Statistics } \\
\hline & $\begin{array}{l}\text { Cronbach's } \\
\text { Alpha }\end{array}$ & $\begin{array}{l}\mathrm{N} \text { of Items } \\
\text { (questions) }\end{array}$ \\
\hline & 0.500 & 4 \\
\hline \multirow{3}{*}{ Overall } & \multicolumn{2}{|c|}{ Reliability Statistics } \\
\hline & $\begin{array}{l}\text { Cronbach's } \\
\text { Alpha }\end{array}$ & $\begin{array}{l}\mathrm{N} \text { of Items } \\
\text { (questions) }\end{array}$ \\
\hline & 0.829 & \\
\hline
\end{tabular}

Calculating Cronbach's alpha indicated us that alpha coefficient bigger than or equal to 0,7 is determined acceptable, and also give enable to good implication for reliability. This estimation is mentioned by Nunnaly (1978) and the main point that excellent indicator of reliability is value of 0.800 which generally accept, also our research data results close to 0.700 are very near to excellent, so is also acceptable according to estimated.

\section{B. Respondents' results on the research questionnaires}

Respondents' answers indicated that the three most important and effective risk identification methods are 1) risk 
audit and inspections, 2) judgments of the banks' managers, 3) process analysis. The data analysis showed that 25 percent of lending managers approach to risks audit and inspections during SMEs' project risk identification. We know that risk identification is the first step for assessing risks, so if managers approach properly, it help them to assess risks comprehensively. The second significant method is SWOT analysis, with mean 4.10 and 19 responses by lending managers, it include 23.75 percent of total respondents. It is important to mention that during SWOT analysis lending manager focus on strengths, weaknesses, opportunities and threats for the project of the SMEs. If they investigated on parts and find properly way to avoid loses, during risk assessment lending manager approach direct to good method. The next important variable for the risk identification cited as a judgments of the banks' risk managers, with mean 2.59 and 18 responses by the lending managers. It is important to say according finding data that internal communications, consulting with employee is a lower important for the lending manager as a method. Because data indicated that 12 respondents approach to this method, it consists of 15 percent of managers who decide loan for the SMEs' sector.

\section{Regression analyses and results analysing}

During regression analysis, the evidence from analysis estimated that the $\mathrm{Z}$ score using for every significant factors and also approached two way interactions, mainly indicated from the individual t-statistics. Regression analysis as an individual subject performs relating significant variables to each other. So, find pattern in our collected data by using this approach. Furthermore, in this our case regression coefficient estimate aggregated among the bank and corresponding $\mathrm{t}$ statistics individually aggregated to an approaching $\mathrm{Z}$ score. Data indicated that the results of regression analysis are aggregated to $\mathrm{Z}$ score for every indicator factors and approached two way interactions estimate lending managers' significance to promote hypothetical loan request. According data analysis and calculation we can see that $Z$ value, its ranks and also unstandardized $B$ for each main factor as following.

Anderson (1971) stated that $\mathrm{Z}$ value calculation estimate which significant factors and selected two way interactions is significant statistically. Mainly Anderson found that when $\mathrm{Z}$ value bigger than 1.645 showed a statistical important at a 5 percent level. Also, if $\mathrm{Z}$ score evaluated greater than 2.3 , it aggregates a significance factors at 1 percent level. Finally, his findings estimated that $\mathrm{Z}$ value bigger than 3.0, it lead to a significant factors at a 0.1 percent level.

TABLE II. THE RESULTS OF REGRESSION ANALYSIS (Z VALUE, ITS RANKS AND UNSTANDARDIZED B)

\begin{tabular}{|l|c|c|c|}
\hline $\begin{array}{c}\text { Main factors for supporting } \\
\text { credit request }\end{array}$ & B & Rank & Z value \\
\hline Competence business project & 48.33 & 1 & 1.76 \\
\hline Past profitability (performance) & 44.02 & 2 & 1.68 \\
\hline Financial standing & 41.29 & 3 & 1.646 \\
\hline Collateral & 33.56 & 4 & 1.21 \\
\hline
\end{tabular}

Data analyzed indicated in this our case that higher the $\mathrm{Z}$ score is leading to competence the business project, with the $\mathrm{Z}$ value is 1.76 . Also, it is important to mention that the size of the $\mathrm{Z}$ values of past profitability (performance) and financial standing factors are higher than 1.645, it means that these two factors are also important for lending managers to decide and give the loan (credit), with $\mathrm{Z}$ scores 1.68 and 1.646 statistically significant respectively for the results.

\begin{tabular}{|c|c|}
\hline Z score & Significance level \\
\hline Greater than 1.645 & $5 \%$ \\
\hline Greater than 2.3 & $1 \%$ \\
\hline Greater 3.0 & $0.1 \%$ \\
\hline
\end{tabular}

NOTE: According to Anderson (1971).

The size of $\mathrm{Z}$ value indicated that the level of significance of the main variables, so we can conclude with competence within the business project being the most significant factors for lending managers to support SMEs' credit request.

Fig.1. SIGNIFICANT FACTORS OF BANK FINANCING SMES' PROJECT AND RESULTS OF THE Z VALUE

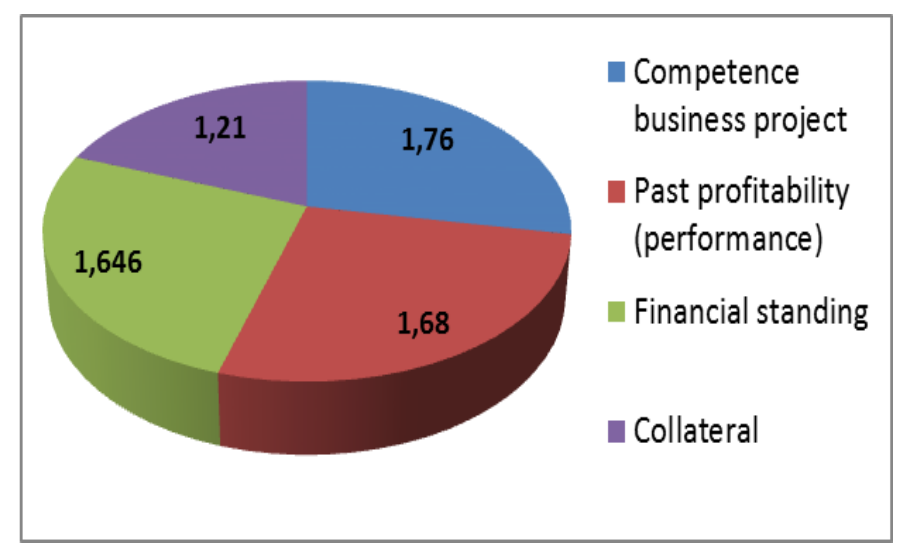

It is also important to say that according to questionnaires' results, we found 21 lending managers linked to this significance. The next importance factor is past performance which past profitability of the SMEs, our findings estimated that with $\mathrm{Z}$ value 1.68 and 22 respondents rated as a significant factors. Also, 19 lending managers approach to financial standing during deciding loan, this is the third importance factor according to data analysis, with $\mathrm{Z}$ value 1.646 and the least significant factor is independence of ordering collateral from SMEs for borrowing loan. Data indicated that the regression coefficients and rank for every factor is examining the magnitude of the significant aggregated standardized. According to findings result estimated that it terms of magnitude, the significant indicator to lending managers' decision making for supporting credit request borrowing of the SME is competence within the business project, with the regression coefficient $0.43(\beta)$. The second the most important 
factor is follows past performance which SMEs' past profitability.

TABLE III. LENDING MANAGERS' PROBABILITY OF SUPPORTING LOAN REQUEST OF THE BORROWING SMES

\begin{tabular}{|l|c|c|}
\hline Statistically significant factors & $\begin{array}{c}\text { Regression } \\
\text { coefficient }(\boldsymbol{\beta})\end{array}$ & Ranking \\
\hline The business project competence & 0.43 & 1 \\
\hline Past profitability (performance) & 0.41 & 2 \\
\hline Financial standing & 0.31 & 3 \\
\hline Ordering collateral & 0.29 & 4 \\
\hline
\end{tabular}

On the other hand, we posted two ways interaction influences were designed; we can see these effects interactions in the Appendix. The last rank leads to independence ordering collateral for supporting SMEs' project by lending managers to decide loan. Significantly that poor education for lending managers or again poor risk identification really effect badly to risk analysis for SME's project.

\section{RESEARCH CONCLUSION AND RECOMMENDATIONS}

\section{A. Discussion for the research paper}

The evidence from the analysis indicates that Aloqabank credit managers is not aware SME risks completely, which are associated with SME activities, within controlling loan and also project. Also, during analysis case study we found the significant of collateral, financial performance demonstrate that factors enable opportunistic behavior for the managers, because lending officer will receive repaying money back to the bank, it is irrespectively of the outcome SME's project, all aspects were valued by lending manager before deciding loan.

According to data analysis and addressed the research objectives what extent lending managers of the Aloqabank understanding and implementing risk assessment for financing SMEs' project, data analysis indicated that credit managers who deciding loan for SMEs' project, has limited implemented capabilities and understanding risks of bank project relatively. Business plan or project concern of SMEs, epically comprehensiveness is the main significant direct effect variable which investigation particular. So, writing of business plan is key part and also endorsed by literature, some universities, supporting agency and other. Business plan enable and suggest that it is one of the vital necessary to the success of SME's project, it will help also managers to manage and identify risks within investigate on business

\section{B. Conclusions according to findings of the paper}

Paper findings indicated that lending managers of Aloqabank investigated deeply on the tangible accounting figures, past performance results, SMEs ordering collateral, all these factors help to managers deciding loan for supporting projects. These factors are like indicators which show project concern to implement or not to finance from bank lending managers. Therefore, data analyzed showed that operational improvements seem to be an important source of repay loan even if the SMEs do not have comparable skills and capabilities. Also, a lower leverage ratio is more likely for the SMEs segment which might be attributed to a lower level of management competencies to handle liabilities.

The research paper also concludes that the findings were grouped into the different approaches to risk assessment of bank financing SMEs. If a sub category was relevant, provided a description based on the interview results. Financial arbitrage, for example, was of no relevance in this case. Furthermore, each risk assessment process and activities was evaluated, regarding its phase and its source.

The team of lending managers has in turn different characteristic such as culture, experience and management level that have to be combined together, to ensure that the projects' deliverables conform to customer requirements and expectations. Also, paper finds one most effective project risk assessment processes are those whose team members facilitate innovation and learning as much as possible.

\section{Recommendations for the future implementation}

Research paper findings recommend to lending managers that their lending decision should be based on good business plan, financial status, cash flow, and also prospects of SMEs. In order to minimize risks of the bank financing projects or shift risks from bank lending managers, should ask reliable collateral, they can identify financial standing of SMEs is solid enough to return loan. Also, there many significant independent variables can influence to managers lending decisions and effect in SME's project performance, such as we can say training with lending managers, bank internal policies or guidelines, referral system of management and others. Lending managers should create strong risk assessment within their investments. It was shown that the SMEs mainly use financial, strategic and also operational improvements measures to higher performance of bank investments, the managers need to focus on this.

\section{ACKNOWLEDGMENT}

I would like to thank Dr. Zhou Qingjie and Dr. Yan Li for supporting and thoughtful suggestions, helped through several part of the paper. We write to extend our warmest gratitude to Beijing Technology and Business University and International Business School, YUFE for giving this great opportunity as well as to attend this International Conference.

\section{REFERENCES}

[1]. Sh. Abdullaeva and A. Omonov, "Business Environment in Uzbekistan as seen by Private Enterprises", International Finance Corporation, World Bank Group, 2009;

[2]. H. Al-Tamimi, "Bank's risk assessment; a comparison study of UAE national and foreign banks". The Journal of Risk Finance, p. 394-409, May, 2007;

[3]. S. Barton and C. Matthew, "Small firms financing: implications from a strategic management perspective." Journal of Small Business Management, vol. 18 (1): 1-7, in 1989;

[4]. A. Carey, "Effective risk management in financial institutions: the Turnbull approach". Balance Sheet, p. 24-27, in 2001;

[5]. M. Fletcher, "Decision making by Scottish bank managers", International Journal of Entrepreneurial Behaviors and Research, vol. 1 (2), 37-53, in 2008; 
[6]. Financial Sector Development in Central and West Asia. "Country Assessment Uzbekistan"; Consultant's report, Asian Development Bank (ADB), 2012;

[7]. P. Ghauri and K. Gronhaug, "Research Methods in Business Studies". 4th Edition; Pearson Education Limited, Essex, England, 2010;

[8]. M. Jensen and W. Meckling, "Theory of the SMEs: managerial behavior, agency costs and ownership structure." Journal of Financial Management, vol. 3: p.305-360, in 1992;

[9]. R. Priem, "An application of metric conjoint analysis for the evaluation of top managers' individual strategic decision making processes". Strategic Management Journal, p.143-151, in 1992;

[10]. Strategy of actions in five priority directions of the Republic of Uzbekistan for 2017-2021 ("Priorities of economic development and liberalization");

[11]. K. Tony, "SME lending decisions: the case of UK and German banks", Studies in Economics and Finance, Vol. 33 Issue 4, p. 501 - 508, in 2016;

[12].World Bank, Uzbekistan, "The World Bank Group's Enterprise Survey" and "Doing Business Uzbekistan - 2015", World Bank database, 2015. 